\title{
O Estado, os conflitos das classes dominantes e a influência do capital estrangeiro na defesa do café no Brasil na Primeira República (1889- 1930)
}

Ednilson Silva Felipe

Professor de Economia da UFES

Programa de Pós Graduação em Economia e do Mestrado em Engenharia e Desenvolvimento Sustentável da UFES

E-mail: ednilsonfelipe.ufes@gmail.com

\author{
Mayara Lyra Bertolani \\ Mestre em Economia pela UFES \\ Analista de estudos e pesquisas do IDEIES \\ E-mail: mayarabertolani@gmail.com
}

Resumo: O foco principal do trabalho é ponderar as medidas adotadas pelo Governo Federal no período da Primeira República, que auxiliaram no progresso da economia agroexportadora brasileira, pautada pela exportação de café. Avalia-se os mecanismos e política para a defesa do café e discute-se em que sentido eles estiveram atrelados - ou não - aos interesses dos cafeicultores e se esses exerciam poder, influência e hegemonia sobre o Estado. A ideia aqui discutira é que o processo de intervenção do Estado na economia foi engendrado por mediações estabelecidas entre o setor público e os diversos grupos que viviam num contexto de luta ideológica e política no interior das classes dominantes. Ao analisar contribuições diversas - e por vezes conflitantes - esse artigo acrescenta, ainda, o papel e influência que exerceu o capital financeiro internacional sobre as ações e políticas estatais. Assim, relativiza-se o debate de influência sobre o Estado, deslocando o eixo de análise não apenas para grupos de interesses nacionais, mas também aqueles localizados em países centrais, financiadores, em última instância, das políticas de valorização.

Palavras-chave: Defesa do café, Primeira República, capital financeiro internacional

Abstract: The focus of this work is to consider the actions taken by the Federal Government in the period of the Primeira República, which helped the progress of the Brazilian agro-export economy, guided by coffee exports. We evaluate the mechanisms and policy for the defense of coffee and discuss in what way they were linked - or not - to the interests of farmers and those exercising power, influence and hegemony over the state. The idea here discussed is that the state intervention process in the economy was engendered by mediations established between the public sector and the various groups living in a context of ideological and political struggle within the ruling classes. By analyzing various contributions - and sometimes conflicting - this article also adds the role and influence exercised international finance capital over the actions and state policies. Thus, we relativize is the influence on the state debate, shifting the axis of analysis not only for groups of national interests, but also those located in the central countries, lenders, ultimately, of the valuation policies.

Key words: Coffee Defense, Primeira República, international financial capital.

JEL Code: N16, N46 
p. 3 - O estado, os conflitos das classes dominantes e a influência do capital estrangeiro...

\section{INTRODUÇÃO}

Ao tomarmos o Estado como parte integrante de uma determinada configuração social, torna-se necessário investigar as características e a natureza das relações que estabelece com outras dimensões constitutivas da sociedade. De acordo com Reis (1985), o Estado desenvolve três modelos de interação que parecem cruciais nesse sentido: i) o primeiro diz respeito à relação Estado e interesses sociais, na qual ganha relevância a função de dominação de classe exercida por este; ii) o segundo modelo de interação é aquele que atribui ao Estado o caráter de mantenedor da ordem social e, por fim, iii) temse a interação que coloca o Estado como competidor de interesses sociais particulares, o que leva a atentar para "o fato de que o ator político em questão compete algumas vezes com as classes dominantes pela extração do excedente e, eventualmente, pelo apoio político das classes subalternas" (REIS, 1985: 170-171).

Tomando-se tais considerações por base, torna-se interessante observar como isso pode ser visto no período da Primeira República e, também, a interação do estado com a cafeicultura. Ou seja, vale investigar as formas de intervenção do Estado, assim como sua relação com os diversos grupos da sociedade e setores econômicos no período, o que contribui de forma fundamental para a análise da evolução do aparato de Estado (e dos seus instrumentos de intervenção) no Brasil sob a Primeira República.

A economia cafeeira, nesse período, foi o principal centro de acumulação de capital, fonte de renda e principal vetor para o desenvolvimento do país. Contudo, em determinados períodos, o café brasileiro enfrentou dificuldades comerciais, às vezes derivadas da superprodução. É importante ressaltar, além disso, que desde meados do século XIX a inserção do Brasil no mercado internacional - e, portanto a entrada de divisas no país - passou a depender fundamentalmente do café. Por essa razão, a economia cafeeira constituía importante lócus de atuação e interação do e com o Estado.

As dificuldades políticas e limitações financeiras do Governo inseriram, porém, outro ator relevante para análise nesse período: os bancos financistas internacionais, que passaram a interferir na vida econômica brasileira, tendo esse capital estrangeiro fluído para o país e se tornado parte importante da explicação da dinâmica econômica nacional. Ademais, em outros períodos o Governo Federal e/ou Estadual adotaram medidas destinadas a sustentar e estabilizar os custos do café, quando efetivamente se chegara a uma situação drástica para a economia cafeeira, com os preços abaixo do custo de produção. Nesses momentos, o capital estrangeiro também apareceu como ator relevante.

O objetivo desse artigo é discutir a atuação e as políticas do Estado brasileiro no período da Primeira República e apresentar em que sentido tais políticas estavam atreladas - ou não - aos interesses da elite cafeeira, confrontando tais interesses com as ações do Governo na política de defesa do setor cafeeiro. Assim, tem a finalidade de analisar em que medida a força da elite cafeicultora moldou as políticas do Governo no período em questão e como se posicionaram as finanças internacionais nesse sentido. Ou seja, soma-se a isso o objetivo de discutir como os interesses do capital estrangeiro também influenciavam o papel e as políticas do Estado nesse período indo de encontro - em algumas vezes, aos interesses dos cafeicultores. 
O artigo está dividido em três partes, além dessa introdução. A seção que segue apresenta visões diferenciadas quanto à influência e hegemonia dos cafeicultores sobre o Estado. Partindo de uma visão de que essa influência seria plena, apresenta-se, logo depois outras duas visões alternativas: a de que as políticas adotadas tinham objetivos mais complexos do que agradar aos cafeicultores e aquela visão que privilegia os elementos políticos como norteadores das ações estatais no período. A seção dois apresenta o papel e a influência do capital financeiro internacional sobre as ações e políticas do estado brasileiro, relativizando a ideia de que este era dominado por grupos de interesses nacionais. A última seção apresenta as considerações finais, seguidas das referências.

\section{AS DISPUTAS PELO CONTROLE DO ESTADO E AS CONTROVÉRSIAS ENTRE A POLÍTICA ECONÔMICA E A DEFESA DO CAFÉ}

\subsection{A simbiose entre o Estado e os interesses dos cafeicultores}

A relação entre Estado, economia e sociedade no Brasil tem sido elemento de análise com o objetivo de averiguar a função que este deve desempenhar na economia em seus principais aspectos. O debate se aprofunda quando se trata das interpretações acerca da posição política e econômica do Governo Federal no período da Primeira República, compreendido entre 1889 até 1930. Há, de certa forma, uma tradição difundida que associa os interesses econômicos dominantes e o controle do Estado nesse período, em que as relações entre este e a oligarquia agroexportadora de café baseavamse na apropriação do primeiro pelos segundos.

Nesta corrente historiográfica, que considera o Estado como um mero instrumento dos grupos economicamente dominantes, de acordo com Perissinotto (1999: 35), estão considerados os "instrumentalistas". Ao examinar a elite política paulista, por exemplo, Love (1982: 215-216) buscou mostrar que esse grupo era homogêneo, originado do interior da elite econômica, sendo, portanto, a elite política do Estado um "comitê executivo da classe dominante". Segundo o autor, era clara a dominação que esse grupo exercia sobre o estado:

A primeira [fase], que corresponde a um período de domínio paulista, começa com a instauração da República e termina pouco antes de a Presidência sair de mãos paulistas. 0 início da segunda fase é marcado pelo crescente recurso do capital externo, a opção por orçamentos estaduais cronicamente desequilibrados e a introdução do programa de valorização, tudo isso acompanhado da diminuição da presença paulista em cargos federais de maior prestígio. Este período caracterizou-se pelo "controle" que São Paulo exerceu sobre as políticas cambial, monetária e cafeeira (LOVE, 1982: 251).

Furtado (1987), nessa mesma linha, argumenta que a política do período era voltada para beneficiar o setor da oligarquia cafeeira, defendendo, desta forma, uma 
p. 5 - O estado, os conflitos das classes dominantes e a influência do capital estrangeiro...

postura de quase total subordinação da política econômica da Primeira República aos interesses do setor cafeeiro. De acordo com o autor,

Durante esse mesmo período, sem embargo, os grupos que exerciam pressão sobre o governo central tornaram-se mais numerosos e complexos. Assinalamos a importância crescente da classe média urbana, na qual se destacava a burocracia civil e militar, diretamente afetada pela depreciação cambial. O importante grupo financeiro internacional, reunido em torno da casa Rothschild, segue de perto a política econômico-financeira do governo brasileiro, particularmente depois do empréstimo de consolidação de 1898. Por último os comerciantes importadores e os industriais, cujos interesses por motivos distintos se opõem aos dos cafeicultores, encontram no regime republicano oportunidade para aumentar o seu poder político. O primeiro esquema de valorização teve de ser posto em prática pelos estados cafeicultores - liderados por São Paulo - sem o apoio do governo federal. [...] O êxito financeiro da experiência [da valorização] veio consolidar a vitória dos recalcitrantes que reforçaram o seu poder e por mais um quarto de século - isto é, até 1930 - lograram submeter o governo central aos objetivos de sua política econômica (FURTADO, 1987: 179-180).

Assim, segundo essa visão, a defesa dos preços propiciava à cultura do café uma conjuntura privilegiada em relação aos demais produtos primários que entravam no comércio internacional. Essa vantagem proporcionada tendia, por conseguinte, a aumentar. Em contrapartida, os elevados lucros criavam para o cafeicultor o estímulo em seguir com seus investimentos, e assim sendo, tornava-se inevitável que essas inversões tendessem a encaminhar-se para a própria cultura do café. Com isso, o mecanismo de defesa da economia cafeeira era, por sua vez, um procedimento de adiamento de um problema que se tornaria cada vez mais grave (FURTADO, 1987).

Havia desse modo, uma situação caracterizada por desequilíbrio entre oferta e procura. Não se podia esperar um aumento da procura como resultante de elevação da renda disponível para consumo nos países importadores, também não se podia pensar em elevar o consumo desses países baixando os preços. Para evitar enormes prejuízos para os produtores e, consequentemente, para o país, retirou-se do mercado parte da produção para que a oferta se elevasse acima do nível que exigia a procura, mantendo um consumo per capita um tanto quanto estável, no curto prazo. Contudo, manter elevado o preço do café traria, novamente no futuro, o desequilíbrio entre oferta e procura. Somado à inviabilidade de utilização dos estoques acumulados - uma vez que a capacidade produtiva continuava a aumentar - tudo isso originaria uma situação insustentável (FURTADO, 1987).

Ao deflagrar-se a crise mundial [...] a produção, que se encontrava em altos níveis, teria de seguir crescendo, pois os produtores haviam continuado a expandir as plantações até aquele momento. Com efeito, a produção máxima seria 
alcançada em 1933, ou seja, no ponto mais baixo da depressão, como reflexo das grandes plantações de 1927-28. Por outro lado, era totalmente impossível obter crédito no exterior para financiar a retenção de novos estoques, pois o mercado internacional de capitais se encontrava em profunda depressão e o crédito do governo desaparecera com a evaporação das reservas (FURTADO, 1987: 186).

A política de defesa do setor cafeeiro na grande depressão concretizou-se em um programa de fomento da renda nacional e, por conseguinte, da renda dos cafeicultores. Exerceu-se uma política anticíclica de grande porte. Furtado ainda reivindica que a recuperação da economia brasileira que se manifestou a partir de 1933 não derivou de fator externo e sim da política, pelo Estado, de fomento que era um subproduto da defesa dos interesses cafeeiros (FURTADO, 1987).

Desta forma e nesta perspectiva, o desenvolvimento da economia agroexportadora brasileira, sua especialização e representatividade, no período, favoreceram a hipótese de uma simbiose entre os interesses exportadores e os interesses do Estado. Isto, porque a intervenção resultou no fortalecimento do setor, haja vista o Estado não ter perdido sua autonomia sob a dominação oligárquica ao envolver-se com setor cafeeiro, pois o café representou no período o eixo estrutural da economia (REIS, 1985). Conforme Oliveira (1995) evidencia,

As receitas do governo federal dependiam em cerca de $75 \%$ dos impostos sobre importação. Uma queda brusca das exportações, provocada por uma alta da taxa cambial, tenderia a diminuir as importações, afetando demasiadamente as receitas do governo federal. Porém, é inegável que a política cambial representou um fator a mais para a expansão da lavoura cafeeira (OLIVEIRA, 1995: 32).

\subsection{Políticas ortodoxas e não os interesses dos cafeicultores: uma visão alternativa}

Essa perspectiva apresentada por Furtado e Love é refutada por outras visões. Visando relativizar as interpretações que designam a oligarquia cafeeira como determinante da condução da política econômica no período, vale visitar as obras de Peláez (1971) e de Villela e Suzigan (1975). Estas se destacam com a hipótese de que a ação estatal no campo econômico do período era influenciada por princípios mercadamente ortodoxos de política monetária, fiscal e cambial. Partem do princípio da existência de homens públicos influentes, pautados pelos ideais ortodoxos, afirmando que tal política - e não os interesses dos cafeicultores - moldaram as condutas públicas do período de forma decisiva.

A ortodoxia definida por Peláez (1971) refere-se ao esforço para a implementação de condições econômicas relacionadas ao reequilíbrio orçamentário, austeridade monetária (redução da oferta de moeda) e controle das taxas de câmbio, sob qualquer 
p. 7 - O estado, os conflitos das classes dominantes e a influência do capital estrangeiro...

condição econômica. Segundo esse autor, "o bem estar econômico de um país depende em grande parte de grandes excedentes comerciais, pronta amortização das dívidas externas, moeda conversível e taxas de câmbios valorizadas" (p.09). Diversos Ministros da Fazenda seriam representantes significativos dessa doutrina, como Rodrigues Alves, Bernardino de Campos, José Leopoldo de Bulhões e Joaquim Murtinho.

No entanto, para Peláez, ainde que esses fossem os objetivos, as políticas econômicas ortodoxas provocaram grave estagnação na economia brasileira, como em períodos de 1898 a 1906.

A ortodoxia é incoerente com quase todas as metas de política econômica nacional. Primeiro, choca-se seriamente com a meta da estabilização econômica, em todas as teorias modernas. Em segundo lugar, a ortodoxia é conflitante com a meta de uma alta taxa de crescimento econômico por retardar a industrialização. [...] Em terceiro lugar, a ortodoxia também entra em conflito com a meta de alocação ótima dos recursos. A sustentação de um preço mínimo para o café, enquanto são implementadas políticas monetárias ortodoxas, impede a diversificação da atividade econômica e assim leva a uma concentração de recursos em uma atividade exportadora de café não promissora. Em quarto lugar, choca-se a ortodoxia com a política social, pois perpetua uma distribuição injusta da renda que é, provavelmente, prejudicial ao crescimento, pelo fato de estar o comando dos recursos concentrado no setor da sociedade com o espírito menos voltado para a indústria (PELÁEZ, 1971: 910).

Rodrigues Alves, por exemplo, em sua segunda administração como Ministro da Fazenda, em 1894, colocou em prática elementos da teoria ortodoxa, entendendo que havia uma relação entre o volume de moeda e a taxa de câmbio e que taxas de câmbio depreciadas tinham impacto negativo na atividade econômica. Para o Ministro, o objetivo era reduzir os déficits do Governo, motivo primário do aumento na oferta de moeda. 0 controle da oferta monetária resultaria, por sua vez, na valorização da taxa de câmbio. 0 capital estrangeiro entraria no país e se alcançaria a prosperidade. Contudo, essa administração não atingiu muitas metas da ortodoxia (PELÁEZ, 1971: 22).

Uma ortodoxia mais rígida, segundo Peláez (1971), foi característica da administração de Bernardino de Campos, do fim de 1896 ao início de 1898. Aplicou-se políticas monetárias ortodoxas durante um período de grave contração dos negócios, com o café, principal atividade econômica do Brasil, sofrendo declínio de preços. Nesse contexto, a ortodoxia monetária entrou em conflito com a meta de estabilização econômica, a mais importante dentre as propostas por Bernardino de Campos, que tinha em mente uma definitiva organização do Brasil no regime do padrão ouroํ. Sendo assim,

\footnotetext{
${ }^{1}$ O Brasil adotou o regime do padrão ouro no período entre 1906 e 1914 e, novamente, entre 1927 e 1930.
} 
A destruição das notas, a redução do volume de moeda através de sua ligação com uma quantidade fixa de ouro, assim como o equilíbrio orçamentário, entraram seriamente em conflito com a estabilização da economia num período de recessão econômica. A valorização da taxa de câmbio simplesmente causaria a falência do setor cafeeiro, devido à queda dos preços do café. Assim, a reforma monetária de Campos era conflitante com qualquer objetivo concebível da política econômica nacional (PELÁEZ, 1971: 24-25).

Em seguida, Joaquim Murtinho, considerado por Peláez (1971) um dos políticos mais importantes da história econômica do Brasil, propôs uma reforma monetária, favorável à valorização do câmbio. Contudo, para o autor, muitas das opiniões de Murtinho sobre formação de capital eram totalmente incompatíveis com o bom senso e com a teoria econômica. Para o Ministro,

Se a taxa de câmbio fôsse nivelada à paridade do ouro, as indústrias ineficientes desapareceriam e assim o Brasil poderia consumir bens importados a preços mais baixos. Também defendia que a depreciação cambial não beneficiava os fazendeiros de café. O bem-estar na realidade não aumentava, pois os fazendeiros tinham que pagar preços mais elevados pelas importações. A renda real era, conseqüentemente, mais baixa. Tendo em vista o forte movimento no sentido da intervenção no mercado do café, a renda real dos fazendeiros seria provavelmente afetada pelo declínio dos preços internacionais e a valorização cambial (PELÁEZ, 1971: 26).

As políticas econômicas de Murtinho foram continuadas pelo seu sucessor, Leopoldo de Bulhões, que tinha como análise da crise brasileira uma visão semelhante a sua. Bulhões defendia que,

[...] as emissões do período do Encilhamento tinham resultado em substancial inflação. A inflação levara a uma inadequada alocação de recursos através da distorção dos preços relativos e das rentabilidades. Por outro lado, o período inflacionário da última década do século XIX resultava numa incerteza para investimentos, tanto do capital nacional quanto do estrangeiro. O único caminho que restava para o Brasil era o da redução das emissões (PELÁEZ, 1971: 39).

Ao referir-se à defesa da economia cafeeira, Peláez (1971: 10-11) afirma que:

[...] ainda que Murtinho, Bulhões e Rodrigues Alves possam não ter acertado em suas políticas de estabilização e instituições monetárias, êles foram absolutamente corretos em seus extraordinários esforços no sentido de evitar o comêço dos programas de suporte do café. 
p. 9 - O estado, os conflitos das classes dominantes e a influência do capital estrangeiro...

Isso porque, para o autor, a depreciação deliberada da taxa de câmbio, de forma a proteger o setor exportador, aumentava os custos das necessidades de capital do setor industrial nascente. Além disso, segundo o próprio Ministro,

Convicto de que a intervenção official só poderia aumentar os nossos males, o Governo deixou que a produção de café se reduzisse por seleção natural, determinando-se, assim, a liquidação e a eliminação dos que não tinham condições de vida, ficando elas nas mãos dos mais fortes e dos mais bem organizados para a lucta (PELÁEZ, 1971: 33).

Assim, de acordo com Villela e Suzigan (1975: 35), as políticas econômicas implantadas no período de 1889 até 1945, foram pautadas "por uma linha tradicional: equilíbrio orçamentário, estabilidade monetária e valorização cambial”, embora tenha havido, nesse período, casos de afastamento dessa linha, devido a fatores internos e externos.

Fritsch (1990; 1985; 1980), sem negar a posição influente da oligarquia cafeeira, questiona o privilégio dessa classe na política econômica adotada pelo Governo Federal, o qual não tinha por objetivo refletir, demasiada e consistentemente, os interesses do setor oligárquico. Ou seja, o autor relativiza a suposição de que o Governo sempre se curvou às pressões da oligarquia do café. Além disso, demonstra seu posicionamento mediante a análise particularizada a respeito da existência de pressões contrárias às valorizações excessivas, e acerca do viés da política cambial.

Deve ser lembrado antes de mais nada que o governo federal efetivamente negou apoio à valorização em situações críticas como em 1906 e 1929; não promoveu a constituição efetiva de uma instituição federal permanentemente dedicada à valorização do café, como demandado por São Paulo na primeira metade dos anos vinte, tendo finalmente retornado sua responsabilidade informal pela defesa dos preços ao governo paulista em fins de 1924, e somente interveio esporadicamente em 1908, 1917, 1921 e, através do Banco do Brasil, em 1923-24 (FRITSCH, 1985: 342).

Desta forma, Fritsch (1990), não se contrapõe a visão da oligarquia paulista como fração hegemônica, como demonstra a seguir.

[...] não existe aqui a intenção de negar o fato de que os representantes políticos dos setores agrícolas, comercial e bancário paulista ligados ao café detinham uma posição hegemônica no Estado brasileiro. [...] A preservação dessa posição foi garantida pela enorme importância da produção cafeeira paulista para o desempenho da economia, pelos mecanismos centralizadores de poder do sistema de controle político implantado durante o Governo Campos Sales, e pela habilidade demonstrada pela oligarquia agrário-financeira paulista em incorporar os interesses da crescente burguesia 
industrial do estado a seus próprios canis de representação política (FRITSCH, 1990:63).

No entanto,

Não se deve perder de vista, entretanto, que o poder de São Paulo não era absoluto, e que nem sempre os políticos paulistas detiveram o controle da máquina política federal extremamente eficaz que seus líderes históricos construíram na virada do século (FRITSCH, 1990:63).

Nas ocasiões em que o Governo Federal concedeu apoio direto ao setor cafeeiro, presenciavam-se sinais evidentes de que ocorreria grave desequilíbrio externo caso os preços do produto oscilassem de acordo com as forças do mercado. Portanto, tal apoio não foi motivado pela intenção de atribuir tratamento privilegiado a esse setor, uma vez que as intervenções no período exerceram forte influência para estabilizar a economia ao evitar desequilíbrios externos, que possivelmente acarretariam em consequências negativas para o desenvolvimento na economia (FRITSCH, 1985). Da mesma forma, o autor evidencia que:

Em relação ao apoio federal à valorização deve ser notado que em uma economia exportadora especializada como a brasileira, a estabilização do preço do produto básico de exportação é talvez a política anticíclica mais eficaz a curto prazo. Portanto, no caso do suporte federal à valorização do café, o interesse nacional e os da indústria cafeeira se confundem.

Em vista disso,

[...] mesmo os casos em que o governo federal interveio diretamente nos mercados de café não podem ser usados, prima facie, como evidência da intenção de proteger os interesses setoriais da cafeicultura uma vez que, nessas ocasiões, estes interesses confundem-se com o interesse nacional (FRITSCH, 1985: 343).

Isto é, medidas que foram favoráveis ao café não se fundamentavam por influências, mas derivavam do fato de a economia brasileira ter sido uma economia exportadora especializada, na qual o processo de acumulação atrelava os interesses do setor exportador com os interesses nacionais. Com isso, crises no setor poderiam desestabilizar a sociedade em geral e, consequentemente, o próprio Estado (PERISSINOTTO, 1999).

\subsection{A história política como fator explicativo da atuação do Estado no período}

Em contrapartida às ideias econômicas tradicionais², têm-se os trabalhos sobre a história política do período, norteada por Fausto (1973). Este, embora tenha reconhecido

\footnotetext{
2 Visão que ilustra a formulação da política econômica pelo Executivo pautada sempre em apoiar programas de valorização do café e que a depreciação do mil réis no período (1889-1930) teria resultado de decisões
} 
p. 11 - O estado, os conflitos das classes dominantes e a influência do capital estrangeiro...

alguns empecilhos enfrentados pela oligarquia do café, enfatizou a posição hegemônica da classe no espectro político nacional. Segundo Fausto (1973: 10-11),

[...] o núcleo agrário-exportador, apesar dos atritos, alcançou seus objetivos básicos: a realização de uma política econômica que garantiu a rentabilidade do setor cafeeiro, apesar da crescente super-produção. Uma rápida menção aos planos valorizadores serve para mostrar como eles sempre triunfaram, em circunstâncias diversas, graças principalmente à sólida base regional de São Paulo. Em fevereiro de 1906, para enfrentar uma situação difícil que combinava a valorização do câmbio com a queda dos preços internacionais, São Paulo, Minas e o Rio de Janeiro firmaram o Convênio de Taubaté, visando impedir a elevação do câmbio e restringir a oferta através de compra pelo governo [...] as operações foram iniciadas por São Paulo sozinho, mas acabaram por arrastar os demais Estados e a União.

Apesar disso, em posterior trabalho, Fausto (1995: 273) afirma que o Estado "não foi um simples clube dos fazendeiros de café. O Estado se definiu como uma integração nacional, que mesmo frágil, nem por isso era inexistente". De acordo com o autor, dependiam do café o crescimento e o emprego e o mesmo fornecia grande parte das divisas necessárias para as importações sendo, portanto, o eixo da economia.

Havia, contudo, uma contradição política entre os interesses econômicos do grupo representante da oligarquia do café e de outros grupos politicamente representados. Desse modo, essa hegemonia não significava o exercício exclusivo do poder, uma vez que havia outros interesses - externos e internos - no conjunto de forças que atuavam no período. Nas palavras do próprio autor:

$\mathrm{Na}$ formulação de sua política, o governo federal não podia ignorar o peso do setor cafeeiro, qualquer que fosse a origem regional do presidente da República. Mas a coisa não era tão simples assim, e vários governantes supostamente ligados aos interesses do café nem sempre agiram como seus defensores. Três presidentes provenientes de São Paulo Campos Sales, Rodrigues Alves e Washington Luís desagradaram ao setor cafeeiro ou se chocaram com ele (FAUSTO, 1995: 273-274).

E ainda, "convém lembrar também que o exercício da hegemonia não se faz sem atritos, pois ela pressupõe a compatibilidade, mas não a identidade de interesses entre diferentes forças sociais" (FAUSTO, 2006: 215-216).

Assim, Fausto (2006) destaca a posição hegemônica da cafeicultura no âmbito político nacional. Esta hegemonia, porém, não denotava o exercício do poder unicamente em benefício próprio, mas sim o compatibilizando com outras classes do país. Além disso,

politicamente motivadas pelo interesse de beneficiar o setor líder da burguesia exportadora (FRITSCH, 1985: 339-340). 
o autor destaca a dependência da economia brasileira e do setor cafeeiro em relação ao setor externo. Posto isto, interesses externos e internos faziam parte do conjunto de forças políticas que atuavam no Brasil.

Analisando essa atuação do Estado durante a Primeira República brasileira, Topik (1987) afirma que sua presença econômica era diretamente proporcional ao seu empenho em representar e defender a economia agroexportadora. Todavia, o objetivo era manter o país em favorável posição mundial, antes de cuidar apenas dos interesses de alguma classe. $\mathrm{O}$ autor considera que as intervenções políticas do Estado foram um produto resultante da economia exportadora, com o intuito de salvá-la do laissez-faire 3 .

Reis (1985) legitima tal ideia enfatizando que a Constituição Republicana de 1891 consagrou o princípio do liberalismo econômico da mesma forma que o do liberalismo político. Contudo, com a consolidação da República nota-se uma crescente pressão dos cafeicultores pela intervenção do poder público na esfera econômica.

Logo, os princípios do laissez-faire teriam dado espaço à intervenção estatal permanente. Essa intervenção política do Estado no domínio econômico se ampliou na Primeira República, não obstante o Estado no Brasil sempre tenha sido intervencionista, apesar de a ordem privada prevalecer durante a Colônia e o Império (FAORO, 2000).

Ainda que a atuação do Estado tenha sido decisiva em determinados momentos de crise da economia cafeeira, Reis (1985) articula que,

[...] existem razões objetivas de Estado que não necessariamente coincidem com aquelas dos interesses sociais dominantes. Assim, por exemplo, a necessidade recorrente de "sanear as finanças públicas" levou o Estado algumas vezes, durante o período que aqui nos interessa, a se contrapor aos interesses agrários dominantes (REIS, 1985: 172).

Ademais, existiam outros grupos políticos que exerciam pressão defendendo seus próprios interesses, os quais às vezes se compatibilizavam com os da cafeicultura, porém, outras vezes, se rebatiam a eles.

Destacam-se três grandes grupos: i) os "interesses internacionais" representados pelos banqueiros, investidores no mercado financeiro internacional e empresas estrangeiras instaladas no Brasil; ii) os demais grupos oligárquicos regionais do país, como aquelas associadas ao açúcar do Nordeste e Rio de Janeiro, à pecuária no Sul e à borracha no Norte; iii) os interesses das classes urbanas, envolvendo funcionários públicos, militares, profissionais liberais, comerciantes, industriais e operários (GREMAUD, 1997).

De acordo com Perissinotto (1994), não havia uma única classe política tida como dominante na economia cafeeira da Primeira República brasileira, mas sim frações autônomas, como, por exemplo, a "lavoura" e a "burguesia comercial urbana", e um

\footnotetext{
${ }^{3}$ De acordo com Topik (1987) o liberalismo econômico era a ideologia dominante durante o período da Primeira República, sendo os fazendeiros e os funcionários públicos, que representavam os interesses da oligarquia exportadora, geralmente favoráveis a programas econômicos baseados no laissez-faire. Entretanto, a política do Estado era norteada por estruturas políticas e econômicas, e não por opções ideológicas.
} 
p. 13 - O estado, os conflitos das classes dominantes e a influência do capital estrangeiro...

conflito existente entre essas frações. Para o autor, a burguesia comercial correspondia ao "grande capital cafeeiro", representando a fração hegemônica, mas como havia um conflito interno entre a classe dominante, nota-se que não se pode considerar a existência de uma classe homogênea: dentro da classe dominante existiram várias frações que a compuseram.

Portanto, dentro da própria classe dominante havia uma relação conflituosa que não era livre de oposições internas. A própria classe cafeicultora não compartilhava interesses homogêneos, havendo, desta forma, uma divergência entre os interesses do grande capital cafeeiro e da lavoura (PERISSINOTTO, 1994).

Desse modo,

Essa imagem unificadora da classe dominante da economia cafeeira paulista é notada claramente em expressões como "burguesia cafeeira" ou "oligarquia paulista", abundantemente encontradas na literatura sobre o período e que, como se vê, têm um sentido generalizador que não identifica frações no seu interior (PERISSINOTTO, 1993: 165).

E mais:

Na formulação da política econômica, certos interesses fundamentais de uma fração da classe dominante são atendidos, e interesses também fundamentais de outras frações não o são. Percebe-se então que a formulação da política econômica de Estado é um campo de luta onde se decidem questões centrais relativas aos interesses de classe, e a sua resultante reflete a relação política entre as frações dominantes (PERISSINOTTO, 1993: 168).

Mesmo São Paulo, centro inquestionável da economia agroexportadora por causa da alta especialização na produção de café, não era livre de conflitos. Além disso, a hegemonia não era exercida unicamente por uma classe interna, o grande capital cafeeiro, mas em conjunto com o capital estrangeiro. Ainda, no que se refere à relação das classes dominantes com os outros interesses da economia nacional, conclui-se que aos conflitos regionais somavam-se, ainda os conflitos no interior das diversas classes.

Deve-se avaliar também que uma desvalorização constante da moeda teria efeitos deletérios sobre as finanças públicas do país, limitando a utilização sistemática de tal política. Além disso, como foi visto, havia uma vulnerabilidade externa da economia brasileira, sendo necessária a adoção de limites ao executar determinadas políticas econômicas. Portanto, as medidas econômicas e políticas adotadas pelo Governo Federal, no período entre 1889 e 1930, ampararam o desenvolvimento do setor cafeeiro, beneficiando não só as classes dominantes, mas também um conjunto mais amplo de interesses, o que mostra que esta classe, apesar de hegemônica, não controlou os planos do governo. 


\section{OS MECANISMOS DE DEFESA, OS FLUXOS FINANCEIROS E A PARTICIPAÇÃO DO CAPITAL INTERNACIONAL}

À discussão sobre a influência nas ações do Estado por grupos hegemônicos, é preciso somar o papel e influência exercidos pelo capital financeiro internacional. Isso porque é impossível desconsiderar a presença desse capital na economia e política do país durante a Primeira República, pois a relação com o capital internacional foi fator determinante para o funcionamento e para a manutenção da economia, assim como para as oscilações da política cambial.

De acordo com Souza (2001), o poderio financeiro de potências capitalistas como a Inglaterra e os EUA levou a intervenção política desses países às conjunturas brasileiras, como na Constituinte de 1889-1891, na qual o país foi pressionado pela manutenção da unidade nacional, a favor de um federalismo moderado. Além disso, pode-se citar que na Revolta da Armada, criou-se uma jurisdição militar estrangeira superior à do Governo, e na Primeira Guerra Mundial, o Brasil sob pressão dos EUA, rompeu a neutralidade e posicionou-se ao lado de potências opostas à Alemanha. Pelo lado econômico e financeiro, este capital agia, na maioria dos casos, como último financiador das políticas e estratégias de valorização do café.

Este capital assumiu posições importantes no financiamento do setor público e nas atividades comerciais. Assim, se fez presente em diversos setores da economia nacional e, sobretudo, no setor de maior dinâmica, o setor cafeeiro. Quanto a este, favoreceu a sua ascensão econômica, ajudou na capacidade de conquistar fortes posições políticas e facilitou os mecanismos de poder para intervir e opinar nas direções da política econômica (PERISSINOTTO, 1994).

Nesse sentido, segundo Fritsch (1990), a política econômica do período foi moldada por restrições impostas aos gestores da política macroeconômica devido à instabilidade da economia, marcada pela vulnerabilidade da posição externa. Em momentos de desequilíbrios macroeconômicos, causados por problemas no balanço de pagamentos, assumia-se a ajuda - e com isso a opinião - dos banqueiros internacionais, ou de seus governos, no ajustamento das opções de política econômica.

É esse uso de recursos externos que provocava, por outro lado, uma condição de dependência estrutural em relação aos atores internacionais, que residia no fato da interferência e determinação da política financeira e cambial, mesmo a contragosto de setores da classe dominante nacional. Assim, o equilíbrio do balanço de pagamento além do tornar-se cada vez mais dependente da manutenção favorável dos preços do café, estava condicionado à propensão de investidores estrangeiros a emprestar ao Brasil.

Mas essa dependência não acontecia apenas no nível do Governo Federal. Em condições de desorganização bancária e com oferta de crédito severamente restrita, os empréstimos se tornavam caríssimos. Essa escassez de crédito no âmbito da lavoura, abria espaço para que o capital estrangeiro, em última instância, surgisse como financiador da cafeicultura - através dos comissários - além, de financiador do Governo, conforme já colocado anteriormente. 
p. 15 - O estado, os conflitos das classes dominantes e a influência do capital estrangeiro...

Assim, além da capacidade de impor ao Estado brasileiro medidas que atendessem seus interesses, o capital estrangeiro tinha a capacidade de impor medidas que desagradavam profundamente os setores produtivos, sendo eles da classe dominante ou não, como no caso do funding loan, em 1898, e nos casos de sustentação dos preços do café (PERISSINOTTO, 1994). Logo, o capital estrangeiro foi, em substancial importância, um elemento central nas decisões acerca da política econômica e cambial do Governo Federal. Contudo, nem mesmo esse grupo de financista era hegemônico. Ao contrário disso, em alguns casos a disputa entre eles (diferentes bancos de diferentes países) era um obstáculo ao fechamento dos projetos e mesmo à condução nos moldes originalmente previstos.

\subsection{O Brasil e a crescente dependência financeira do capital internacional}

Durante longos períodos o investimento britânico no Brasil foi predominante e apresentou em crescimento bastante significativo, como demonstra a tabela abaixo.

Tabela 1 - Investimentos Britânicos no Brasil (milhões de libras)

\begin{tabular}{l|l}
\hline Ano & Brasil \\
\hline 1880 & 38,8 \\
\hline 1890 & 68,6 \\
\hline 1900 & 90,6 \\
\hline 1913 & 223,8 \\
\hline 1928 & 287,3 \\
\hline
\end{tabular}

Fonte: Adaptado de RIPPY, 1950 apud SILVA, 1980: 37.

Segundo Singer (2006) mais da metade dessa soma de investimentos britânicos foi representada por empréstimos ao Governo brasileiro, sendo o restante inversão privada. Após 1890, os empréstimos públicos adquiridos no exterior se destinaram em maior parte às obras públicas, em geral construção de portos e ferrovias ou a sustentação do principal produto de exportação, o café. Mesmo assim, existiu a dificuldade no resgate das dívidas, levando sua consolidação a partir de funding loans, o primeiro em 1898 e o segundo em 1914. Prado Júnior (1998: 223) afirma que:

O grande beneficiário das reformas de 1898 foi sem dúvida a finança internacional. Representada neste caso pelo London \& River Plate Bank, intermediário do acordo com os credores, ganhará novas posições no Brasil e junto a seu governo. Os seus representantes assumirão o direito de velarem diretamente pelo cumprimento do acordo feito, e fiscalizarão oficialmente a execução das medidas destinadas a restaurar as finanças do país. Entrelaçam-se assim intimamente seus interesses e suas atividades com a vida econômica e administrativa brasileira. E ela não Ihes poderá mais tão cedo fugir. Consolidara-se uma situação de dependência que se vinha 
formando havia muito, mas que somente agora encontrará seu equilíbrio definitivo.

O crescimento da dívida pública confirma a ascensão da dependência financeira do Brasil. Durante o Império o Brasil havia feito 17 empréstimos; em 41 anos de República o país atingiu 27 empréstimos (PERISSINOTTO, 1994). Em 1889 a dívida externa brasileira se situava na casa dos 30 milhões de libras. Em 1910, essa dívida passou para 90 milhões, subindo para 250 milhões, em 1930 (PRADO JÚNIOR, 1998).

Tabela 2-Dívida Externa Consolidada da União - Em mil Libras Esterlinas (anos selecionados)

\begin{tabular}{l|l|l|l}
\hline Ano & & & \\
\hline 1898 & 35.731 & 1915 & 108.629 \\
\hline 1900 & 41.009 & 1918 & 116.432 \\
\hline 1903 & 65.752 & 1921 & - \\
\hline 1906 & 69.821 & 1924 & - \\
\hline 1909 & 80.602 & 1927 & \\
\hline 1912 & 93.334 & 1930 & 259.900 \\
\hline
\end{tabular}

Fonte: Torelli (2004)

A origem dos empréstimos que implicavam diretamente no aumento da dívida pode ser vista abaixo:

Tabela 3-Número e valor dos Empréstimos Concedidos ao Governo Brasileiro - (1881 1931)

\begin{tabular}{l|l|l|l|l|l|l}
\hline \multirow{2}{*}{ Período } & \multicolumn{2}{|l|}{ Grã-Bretanha } & \multicolumn{2}{l|}{ Estados Unidos } & \multicolumn{2}{l}{ França } \\
\cline { 2 - 7 } & n. & $\begin{array}{l}\text { Valor } \\
\text { Mil Libras }\end{array}$ & n. & $\begin{array}{l}\text { Valor } \\
\text { Mil Dólares }\end{array}$ & n. & $\begin{array}{l}\text { Valor } \\
\text { Mil FF }\end{array}$ \\
\hline $1881-1890$ & 4 & 37.165 & - & - & - & - \\
\hline $1891-1900$ & 3 & 19.766 & - & - & - & - \\
\hline $1901-1910$ & 4 & 40.139 & - & - & 3 & 240.000 \\
\hline $1911-1920$ & 4 & 32.402 & - & - & 2 & 85.000 \\
\hline $1921-1931$ & 3 & 28.281 & 5 & 176.500 & 3 & 215.000 \\
\hline
\end{tabular}

Fonte: Torelli (2004)

Essa contínua dependência financeira permitiu "aos credores externos imporem condições draconianas quando a falta de recursos obrigava o Governo a suspender o serviço da dívida externa" (SINGER, 2006: 398), fazendo-o pagar muito mais do que o recebido, com juros exorbitantes (PERISSINOTTO, 1994). Faoro dá outro exemplo do comportamento desses financistas internacionais:

Os investidores estrangeiros, inclusive os bancos, forçados a remeter juros e lucros, pressionam o governo para o câmbio alto, bem como cuidam da solvência do Tesouro. Na 
p. 17 - O estado, os conflitos das classes dominantes e a influência do capital estrangeiro...

cúpula, como símbolo da realidade, a casa Rothschild de Londres, agente financeiro do país desde 1855, impacientemente reclama o restabelecimento da sanidade financeira e cambial (FAORO, 2001: 17)

E outro: "num empréstimo de tipo 80, por exemplo, de 1.000 libras emprestadas recebíamos apenas 800 . Os outros 200 seriam distribuídos entre comissões, frete do ouro, juros etc" (CARONE, 1972 apud PERISSINOTTO, 1999: 181). A razão desse crescente endividamento e o motivo pelo qual o Brasil precisava recorrer consistentemente aos empréstimos estrangeiros é explicada por Perissinotto (1994: 182):

O que existia de fato era uma dependência financeira estrutural em função do predomínio quase que absoluto da economia agroexportadora, isto é, em função do lugar ocupado pelo Brasil na divisão internacional do trabalho como mero exportador de bens primários. O baixo desenvolvimento de nossas forças produtivas determinava o lugar ocupado pelo Brasil na divisão internacional do trabalho. Éramos um país exportador de bens primários. Como tal, o ponto dinâmico de nossa economia residia todo ele na produção exportadora, deixando a atividade produtiva voltada para o mercado interno numa posição completamente secundária.

Havia ainda, segundo o autor, um agravante. A estrutura tributária era proveniente do imposto sobre as importações, e este era responsável pela capacidade financeira do Estado brasileiro. O volume das importações dependia da capacidade para importar determinada pelo setor cafeeiro, pois era o ouro proveniente do café que pagava as importações. Logo, crises no setor cafeeiro afetavam em demasia as finanças do Estado, tornando o Brasil um país sem recursos financeiros que lhe permitissem arcar com seus compromissos internos e externos. Como saída, o Estado recorria a empréstimos externos.

Portanto, um país exportador de bens primários como o Brasil, sem uma forte atividade interna, profundamente dependente das importações e dos empréstimos externos, completamente descapitalizado, tornava-o estruturalmente dependente do financiamento externo de sua economia. Recorrendo aos empréstimos externos, o Brasil reiterava a sua condição de dependência e acentuava sua evasão de divisas via pagamento de juros ${ }^{4}$ (PERISSINOTTO, 1994).

A questão fundamental é que o capitalismo que se formava exigia, cada vez mais, um equilíbrio financeiro das economias nacionais, para que se assegurasse o pagamento de juros ao capital emprestado. Por isso, o estado brasileiro, ao aceitar as condições que Ihe eram impostas, adotava um tipo de política de subserviência, com ênfase no pagamento de dívidas externas e passava a desempenhar um papel específico nessa

\footnotetext{
${ }^{4}$ Sobre a evasão de divisas ver Oliveira (2006).
} 
configuração: a de entregador de renda ao capital financeiro internacional. Segundo Torelli (2004: 100), Cardoso de Mello tinha essa mesma visão como pode ser vista abaixo:

Nesta nova lógica capitalista, a periferia não era mais apenas produtora de bens primários e matérias-primas e compradora dos insumos industriais produzidos pelo centro, era, também, necessário agora que parte das nações periféricas possuíssem estruturas estatais e econômicas com capacidade de contrair empréstimos e atrair investimentos estrangeiros diretos para reproduzir o capital financeiro do centro.

\subsection{O capital estrangeiro na economia cafeeira}

Apesar de atuar em toda a economia nacional, a presença do capital estrangeiro deve ser analisada em específico na economia cafeeira, pois esta era a principal atividade econômica, mais dinâmica e, principalmente a mais lucrativa. Por isso, o capital estrangeiro se dirigiu em maior parte para esse setor, através da comercialização do café e do financiamento das valorizações.

O desenvolvimento da lavoura cafeeira não teria sido possível sem os capitais e créditos fornecidos pela finança internacional. Grande parte dos fundos necessários ao estabelecimento das plantações e custeio da produção era proveniente de bancos ingleses e franceses, ou de casas exportadoras de café. Em 1906 os preços, que estavam em declínio desde antes, chegaram, com a valorização da moeda, a um nível abaixo do custo de produção. Os prejuízos da lavoura foram consideráveis. Todavia a posição mundial do comércio cafeeiro não era desfavorável. Optou-se, como solução, por um expediente oportunista que consistirá em intervir no mercado com compras maciças para forçar a alta (PRADO JÚNIOR, 1998).

Todavia, segundo o autor, encontrou-se dificuldade para obtenção de recursos necessários, uma vez que seria insuficiente contar somente com as finanças nacionais. $O$ crédito estrangeiro encontrou barreiras com a recusa dos banqueiros e agentes financeiros do Brasil no exterior.

A recusa dos Rothschild em financiar inicialmente o Convênio de Taubaté é um exemplo dessa situação. Essa Casa temia que o abandono dos parâmetros ortodoxos repercutisse negativamente no pagamento dos serviços da dívida externa brasileira. De acordo com Oliveira (1995:62) essa se apresenta como "a mais ferrenha inimiga da valorização e da caixa de conversão". A pressão dos Rothschild também influenciava a decisão de outros banqueiros internacionais em não favorecer as operações.

Há de se considerar, também, que esse período representa uma disputa entre grupos financeiros internacionais para a expansão capitalista, em que tais grupos buscavam locais onde pudessem obter elevado retorno de seu capital. Mantidas as mesas 
p. 19 - O estado, os conflitos das classes dominantes e a influência do capital estrangeiro...

pressões sobre o Governo, a recusa de um grupo abria porta para outros ampliarem seus domínios e interesses no Brasil (PRADO JUNIORR, 1998)

Dessa forma, entraram em cena outros grupos financeiros buscando em seu favor o controle do comércio do café. Esse esquema valorizador, de 1906, permitiu a entrada de capitais originários de países como a França, Alemanha e Estados Unidos, devido à inicial recusa dos Rotchschilds em financiar o plano. A partir de então, créditos de diversos países são colocados à disposição e, com isso, entre 1906 e 1910 foram retiradas 8.500.000 sacas de café do mercado livre (PERISSINOTTO, 1994).

Formou-se uma comissão denominada Comissão do Café do Estado de São Paulo, na qual os banqueiros eram quase unanimidade, (cinco membros contra um de nomeação do governo paulista). Assim, as sacas estocadas passaram para o controle desse comitê, e a mercadoria adquirida seria revendida com alta margem de lucro; e os estoques oficiais retirados do mercado, segundo Prado Júnior (1998), ficariam sob o comando dos interesses financeiros envolvidos, que ficaram por muito tempo com o controle completo do mercado cafeeiro. De acordo com Delfim Netto (2009: 60),

Do ponto de vista dos comerciantes que participaram da operação, esta foi bem-sucedida, pois eles, além de receberem juros e comissões, puderam aproveitar-se das elevações dos preços. Não foi menor o lucro dos banqueiros, que receberam mais ou menos $9 \%$ sobre o capital emprestado.

Do ponto de vista da economia nacional, Souza (2001) esclarece que a valorização evitou que os preços em moeda nacional ficassem muito abaixo dos custos da produção, devido à enorme safra de 1906, o que ocorreria caso a operação de valorização não tivesse acontecido. Esse esquema valorizador também manteve uma fonte de lucro intacta para o capital comercial estrangeiro e nacional. Por isso, para este capital era fundamental o sucesso do plano, e por esse fator, empenhou-se em assegurar recursos junto aos banqueiros internacionais para o estado de São Paulo sustentar a operação.

No período de conflito mundial, período este em que fez cair as exportações e o preço do café, não coube alternativa ao Governo Brasileiro senão realizar a segunda defesa do produto através da emissão de moeda. Após esse período de anormalidade da Primeira Guerra Mundial, segundo Perissinotto (1994), a burguesia financeira internacional voltou a exercer seu domínio no financiamento dos negócios cafeeiros. Posto isto, o capital financeiro internacional impôs sua política, ou seja, o abandono das emissões e a realização do terceiro esquema valorizador, baseado em empréstimos externos. Do mesmo modo,

\footnotetext{
${ }^{5}$ De acordo com Oliveira (1993:65), em relação à primeira valorização, "a Casa Rothschild percebendo a atuação de outros grupos financeiros nas operações de valorização, decidiu rever suas posição inicial, passando não só a apoiar como a fornecer recursos para as operações. [...] As condições do empréstimo de 15 milhões de libras esterlinas modificaram ainda mais os rumos da intervenção, pois praticamente forneceram aos banqueiros e aos exportadores o controle do programa de valorização."
} 
Mais uma vez, os fazendeiros se encontraram impotentes diante da força do capital estrangeiro, novamente o Estado se viu como mero garantidor dos empréstimos efetivados e, novamente, os grupos internacionais garantiram a sua preponderância econômica e política dando a última palavra sobre as decisões concernentes ao nosso principal produto. A especulação comercial apareceu como pretexto para se iniciar a defesa permanente do café. [...] Quanto ao capital estrangeiro, mais uma vez ele conseguiu bloquear reivindicações da lavoura que exigiam as emissões para o financiamento da defesa permanente (PERISSINOTTO, 1994: 177).

Ou seja, o governo brasileiro cedeu à pressão dos credores internacionais não realizando a política de emissão monetária e, em decorrência disso, realizou novamente empréstimos externos. Além disso, as cláusulas dos contratos que permitiram a obtenção de 9 milhões de libras em empréstimo dos Rothschild, Baring Brothers e J. Schroeder impediam que o Governo realizasse novas operações de valorização sem autorização dos banqueiros credores. "A indignação dos fazendeiros foi maior ainda porque o governo federal delegou aos banqueiros estrangeiros o processo de valorização ao invés de entregá-la aos interessados imediatos e à capacidade comprovada do Estado de São Paulo (OLIVEIRA, 1993:76).

Dessa forma, esse poder que o capital internacional exerceu de impor seus critérios na realização das políticas econômicas deixou evidente a constante reprodução de um capitalismo dependente (SOUZA, 2001). Por essa ótica, as críticas à terceira valorização ganharam um conteúdo fortemente nacionalista.

Desta forma, segundo Fritsch (1985), em ocasiões que o governo não interveio no mercado cafeeiro, agiu de tal forma devido às pressões de grupos politicamente fortes. Foram vários os casos paradigmáticos. A começar pelos banqueiros londrinos, quando eram contrários a essa intervenção, questionando os riscos financeiros da valorização. Quando interveio, o fez também sob os ditames e condições estabelecidas ou moldadas pelos financiadores internacionais. Quando do desenho da defesa permanente, o discurso era de que as intervenções temporárias em nada tinham resolvido o problema do produtor:

Efetivamente, qual a vantagem econômico-social durável, que promoveu em benefício da classe dos lavradores? Absolutamente nenhuma vantagem, que permanecesse além das escassas semanas ou meses, em que foi posto em execução. Então, a quem beneficiou os planos? Aproveitou (cruel ironia) aos que absolutamente não se buscou beneficiar, às classes dos banqueiros, comerciantes ou comissários, que de nenhum auxílio necessitavam. ${ }^{6}$

\footnotetext{
${ }^{6}$ Fragmento do discurso de Silvio Alvares Penteado, em Oliveira (1993:83).
} 
p. 21 - O estado, os conflitos das classes dominantes e a influência do capital estrangeiro...

Por isso, os cafeicultores propunham seu funcionamento sobre dois princípios básicos: a) um mecanismo de controle de estoques nas mãos dos brasileiros e não dos exportadores estrangeiros e b) um mecanismo de financiamento que não fosse inflacionário, mas que também não comprometesse a soberania nacional, com os empréstimos externos (OLIVEIRA, 1993).

Já na década de 1920, a oposição dos banqueiros estrangeiros, bem como do governo norte-americano, em relação aos controles de oferta de produtos primários, levou a decisão de liquidar a defesa federal em 1924. No último governo da Primeira República, as restrições estabelecidas pela campanha presidencial, a dificuldade de confrontar os banqueiros internacionais e a "idée fixe de Washington Luis a respeito das vantagens da preservação do padrão-ouro", influenciaram a recusa do governo federal em garantir suporte financeiro ao Instituto do Café de São Paulo, em 1929 (FRITSCH, 1985: 343).

\section{CONSIDERAÇÕES FINAIS}

O predomínio da economia agroexportadora e a presença do capital estrangeiro na economia cafeeira garantiram alguns benefícios ao grande capital cafeeiro. A perpetuação da intermediação do capital estrangeiro proporcionava ao próprio e ao grande capital cafeeiro posições privilegiadas na economia agroexportadora. Além disso, a presença do capital estrangeiro na economia cafeeira proporcionou ao grande capital a possibilidade de associação com estes lucros exorbitantes. Essa associação permitiu uma concordância em relação às formas de comercialização do café e, algumas vezes, à de política cambial (PERISSINOTTO, 1994).

Em contrapartida, no caso dos produtores de café, havia, por um lado, uma relação harmoniosa, no que diz respeito à vocação agrária e ao protecionismo industrial, e por outro lado, uma relação extremamente conflituosa. A lavoura criticava o monopólio da comercialização do café pelo capital estrangeiro, a especulação realizada por ele e sua participação hegemônica nos esquemas valorizadores. Outro fator de discordância era a questão da política cambial, que muitas vezes esteve em oposição aos interesses da lavoura cafeeira e guiada pelos anseios do capital internacional.

Portanto, os funding loans, em 1898 e 1914, foram uma imposição do capital estrangeiro, assim como a valorização do câmbio. A lavoura, por sua vez, foi diretamente afetada pela realização da política de valorização, entre 1898 a 1906, tendo como consequência a expansão da oferta e, em seguida, a queda constante dos preços internacionais do café. Desta forma, a internalização do capital estrangeiro implicou, em certos momentos, o abandono de alguns interesses fundamentais da lavoura cafeeira, que era uma fração da classe dominante nacional.

Evidentemente, havia uma supremacia do setor externo mesmo em ocasiões quando houve tentativas de reduzir a dependência externa, como entre 1889-1894 e entre 1906 e 1914, pois predominava a convicção de que o capital internacional viria para estimular e era fundamental parao desenvolvimento (TOPIK, 1987). 
Assim sendo, não foram os produtores nem os fazendeiros de café que dirigiram plenamente a política econômica do Estado, por conta própria. Muitas vezes tiveram que enfrentar políticas monetárias e cambiais contrárias aos seus interesses, impostas por pressão de credores e investidores financeiros. Estes queriam facilitar o fluxo de capitais internacionais no Brasil, opondo-se às políticas expansionistas, em alguns momentos defendidas pelos agricultores.

Em vista disso, o período da Primeira República brasileira foi caracterizado, em grande parte, pela capacidade do capital financeiro impor políticas de ajustes financeiros e controle da política econômica do governo federal, tendo, portanto, papel determinante no que diz respeito às operações de valorização do café.

Ainda, é evidente que o apoio do Governo Federal às valorizações do produto atenuou os momentos de crise que se abateram sobre o setor cafeeiro, embora em alguns momentos notou-se a relutância do governo em intervir. Além disso, de acordo com Delfim Netto (2009), houve condições extremamente favoráveis para o êxito dessas políticas. O Estado, quando efetivamente, entrou no mercado de café, o fez, pois os seus interesses estavam intrínsecos às ações valorizadoras do setor, visto que o café era o alicerce da economia.

O que havia, de fato, era uma dependência financeira em função da preponderância da economia agroexportadora. Logo, as defesas do café representaram um mecanismo para garantir ao Estado brasileiro sua "sobrevivência", uma vez que garantir preços favoráveis denotava capacidade de importar e certo controle sobre o balanço de pagamentos, mesmo com o crescimento do endividamento externo.

\section{REFERÊNCIAS}

DELFIM NETTO, Antônio. O problema do café no Brasil. São Paulo: Editora UNESP, 2009. FAORO, Raymundo. Os donos do poder: formação do patronato político brasileiro. 15. ed. São Paulo: Globo, 2000.

FAUSTO, Boris. Expansão do café e política cafeeira. In: (Dir.).História Geral da Civilização Brasileira. Tomo III - O Brasil republicano. v.8. Estrutura de poder e economia (1889-1930). Rio de Janeiro: Bertrand Brasil, 2006.

História do Brasil. 2. ed. São Paulo: Editora da Universidade de São Paulo Fundação do Desenvolvimento da Educação, 1995.

Pequenos Ensaios de História da República (1889-1945). In: Cadernos CEBRAP,

São Paulo, n. 10, 1973.

FRITSCH, Winston. Aspectos da Política Econômica no Brasil, 1906 - 1914. In: NEUHAUS, Paulo (Org.). Economia Brasileira: uma visão histórica. Rio de Janeiro: Campus, 1980. . Sobre as interpretações tradicionais da lógica da política econômica na Primeira República. In: Revista Estudos Econômicos. v.15. São Paulo: USP/IPE, n.2. 1985.

Apogeu e crise da Primeira República: 1900-1930. In: ABREU, Marcelo Paiva

(Org.). A ordem do progresso: cem anos de política econômica republicana: 1889-1989. Rio de Janeiro: Campus, 1990.

FURTADO, Celso Monteiro. Formação Econômica do Brasil. São Paulo: Editora Nacional, 1987. 
p. 23 - O estado, os conflitos das classes dominantes e a influência do capital estrangeiro...

GREMAUD, Amaury Patrick. Das Controvérsias Teóricas à Política Econômica: Pensamento Econômico e Economia Brasileira no Segundo Império e na Primeira República (1840 - 1930). 1997. Tese (Doutorado em Economia). Faculdade de Economia, Administração e Contabilidade da Universidade de São Paulo.

HOLLOWAY, Thomas H. Vida e morte do Convênio de Taubaté: a primeira valorização do café. Rio de Janeiro: Paz e Terra, 1978.

LOVE, Joseph. A locomotiva: São Paula na federação brasileira 1889-1937. Rio de Janeiro: Paz e Terra, 1982.

OLIVEIRA, Elizabete Rodrigues. A intervenção do Estado na economia cafeeira na Primeira República: as relações entre o setor público e o privado. 1995. Dissertação (Mestrado em Administração Pública). Fundação Getúlio Vargas - Escola de Administração de Empresas de São Paulo.

OLIVEIRA, Francisco de. A emergência do modo de produção de mercadorias: uma interpretação teórica da economia da República Velha. In: FAUSTO, Boris (Dir.). História Geral da Civilização Brasileira. Tomo III - O Brasil republicano. v.8. Estrutura de poder e economia (1889-1930). Rio de Janeiro: Bertrand Brasil, 2006.

PELÁEZ, Carlos Manuel (1971) As Conseqüências Econômicas da Ortodoxia Monetária, Cambial e Fiscal no Brasil entre 1889-1945. In: Revista Brasileira de Economia, n. 25 (3), julho/setembro.

PERISSINOTTO, Renato M. Estado e Capital Cafeeiro em São Paulo, 1889-1930. Tomo I. São Paulo: FAPESP; Campinas, SP: UNICAMP, 1999. . Classes dominantes e hegemonia na República Velha. Campinas: Editora Unicamp, 1994. . Classe dominante e política econômica na economia cafeeira (1906-1930). In: Revista Perspectivas, São Paulo, 16: 165-189, 1993.

PRADO JÚNIOR, Caio. História econômica do Brasil. São Paulo: Brasiliense, 1998.

REIS, Elisa Pereira. Interesses agro-exportadores e construção do Estado: Brasil de 1890 a 1930. In: CARDOSO, Fernando Henrique; FONT, Maurício Augusto; SORJ, Bernardo. Economia e Movimentos Sociais na América Latina. São Paulo: Brasiliense, 1985.

SILVA, Sergio. Expansão cafeeira e origens da indústria no Brasil. 7.ed. São Paulo: Editora Alfa-Omega, 1986.

SINGER, Paul. O Brasil no contexto do capitalismo internacional. In: FAUSTO, Boris (Dir.). História Geral da Civilização Brasileira. Tomo III - O Brasil republicano. v.8. Estrutura de poder e economia (1889-1930). Rio de Janeiro: Bertrand Brasil, 2006.

SOUZA, Angelita Matos. Estado e dependência no Brasil (1889-1930). São Paulo: Annablume: 2001.

TOPIK, Steven. A presença do estado na economia política do Brasil de 1889 a 1930. São Paulo: Record, 1987.

VILLELA, Anníbal; SUZIGAN, Wilson. Política do governo e crescimento da economia brasileira, 1889-1945. Rio de Janeiro: IPEA/INPES, 1975. 